\title{
SISTEM PAKAR MENDETEKSI MALNUTRISI PADA REMAJA DENGAN METODE FORWARD CHAINING
}

\author{
Dwiny Meidelfi ${ }^{1}$, Salman Alfarissy $^{2}$, Afrizal Fauzi $^{3}$, Richy Azura ${ }^{4}$ \\ Teknologi Rekayasa Perangkat Lunak/Teknologi Informasi, PoliteknikNegeri Padang ${ }^{1,2,3,4}$ \\ Email :dwinymeidelfi@pnp.ac.id ${ }^{1}$ salman.alfarissy26@ gmail.com², \\ afrizal.fauzi.1600@gmail.com ${ }^{3}$,richy.azura10@gmai.com ${ }^{4}$
}

\begin{abstract}
ABSTRAK
Masa remaja merupakan masa transisi, dimana seorang remaja tumbuh menuju kedewasaan. Yang dimaksud dengan kedewasaan adalah kedewasaan dalam pengertian emosi, cara berpikir dan berperilaku. Saat ini banyak hal yang mempengaruhi kedewasaan remaja selain lingkungan, juga perkembangan teknologi yang membuat remaja semakin lalai dan melupakan tugas-tugas yang harus dijalani remaja. Perkembangan teknologi mempunyai pengaruh yang sangat besar pada remaja saat ini, selain membuat mereka lalai dalam menjalankan tugasnya juga membuat mereka lalai dalam menjaga kesehatannya terutama kesehatan fisik, dimana pada saat ini remaja hanya fokus pada laptop dan smartphone saja, sedangkan untuk nutrisi Mereka lupa, sehingga banyak remaja saat ini yang mengalami malnutrisi. Pada penelitian ini bertujuan untuk merancang sistem pakar yang dapat membantu mendeteksi malnutrisi pada remaja dengan menggunakan metode forward chaining. Penelitian ini diharapkan dapat membantu orang tua dalam melacak malnutrisi pada anak remaja mereka.
\end{abstract}

Kata Kunci: Forward Chaining,Malnutrisi, Remaja, Sistem Pakar.

\begin{abstract}
Adolescence is a transitional period, where a teenager grows towards adulthood. What is meant by maturity is maturity in terms of emotions, ways of thinking and behaving. Currently, many things affect adolescent adolescence apart from the environment, as well as technological developments that make adolescents more negligent and forget about the tasks that have to be undertaken by adolescents. Technological developments have a very big influence on today's adolescents, apart from making them neglectful in carrying out their duties it also makes them neglectful in maintaining their health, especially physical health, where currently teenagers only focus on laptops and smartphones, while for nutrition they forget, so many teenagers today are experiencing malnutrition. This study aims to design an expert system that can help detect malnutrition in adolescents using the forward chaining method. This research is expected to help parents in tracking malnutrition in their teenagers.
\end{abstract}

Keywords: Forward Chaining,Malnutrition, Teenager, Expert System.

\section{PENDAHULUAN}

Saat ini banyak kasus gizi buruk yang terjadi di Indonesia.Gangguan nutrisi pada usia dini akan berdampak terhadap kehidupan selanjutnya(Kartika et al.,
2016).Selain anak/balita yang terkena gizi buruk, Salah satu kelompok yang rentan mengalami masalah gizi adalah remaja. Remaja atau adolescence dalam bahasa 
latin (adolescare) yaitu tumbuh untuk mencapai kematangan(Danty et al., 2019).

Kelompok Remaja merupakan salah satu perhatian utama di bidang kesehatan.Hal ini disebabkan karena keunikan gaya hidup remaja apabila dibandingkan dengan kelompok usia lain(Valentina \& Debora, 2013).

Pada zaman sekarang banyak remaja yang kurang dalam memperhatikan kesehatan tubuhnya, bahkan orang tua pun juga kurang dalam memperhatikan pola asupan nutrisi anak remajanya, sehingga di Indonesia sendiri banyak remaja yang terkena gizi buruk.Berdasarkan data Riskesdas 2018 menunjukkan bahwa $25,7 \%$ remaja usia $13-15$ tahun dan $26,9 \%$ remaja usia 16-18 tahun dengan status gizi pendek dan sangat pendek.Selain itu terdapat $8,7 \%$ remaja usia $13-15$ tahun dan $8,1 \%$ remaja usia $16-18$ tahun dengan kondisi kurus dan sangat kurus. Sedangkan prevalensi berat badan lebih dan obesitas sebesar $16,0 \%$ pada remaja usia 13-15 tahun dan $13,5 \%$ pada remaja usia $16-18$ tahun (Kementrian Kesehatan RI, 2020).Dari data teresebut kita bisa tahu bahwa Indonesia sendiri termasuk cukup besar dalam kasus gizi buruknya.

Untuk mengurangi kasus gizi buruk pada anak-anak atau pun remaja, di butuhkan peranan dari orang-orang terdekat dalam melakukan pemantauan terhadap anak mereka,karena kebanyakan kasus gizi buruk itu di alami oleh balita,anak-anak dan remaja.Pada zaman sekarang yang paling berpotensi terkena gizi buruk adalah anak remaja, dimana kebanyakan dari mereka lebih fokus dengan smartphone dan laptop sehingga asupan nutrisi untuk tubuh,mereka Suka lupa.Jadi Pada paper ini akan membahas tentang sistem pakar yang akan membantu orang tua dalam mendeteksi malnutrisi pada anak remajanya.

Sistem pakar pada kajian ini sengaja dirancang berbasis web,sehingga dapat dengan mudah di akses dimana saja dan kapan saja, sebagai alternative konsultasi dan pemberian informasi yang lebih mudah.Diharapkan dengan adanya sistem pakar ini dapat membantu mengurangi kasus gizi buruk yang terjadi di Indonesia.

\section{LANDASAN TEORI}

2.1. Kecerdasan Buatan (Artificial Intelligence)

Kecerdasan buatan berasal dari Bahasa inggris "Artificial Intelligence" atau disingkat AI yaitu intelligence adalah kata sifat yang berarti cerdas, sedangkan artificial artinya buatan. Kecerdasan buatan yang dimaksud disini merujuk pada mesin yang mampu berfikir, menimbang tindakan yang akan diambil, dan mampu mengambil keputusan seperti yang dilakukan oleh manusia(Batam, 2017). Agar komputer dapat bertindak seperti dan sebaik manusia, maka komputer harus diberi bekal pengetahuan dan kemampuan untuk menalar(Septiani \& Kuryanti, 2019). "Sistem cerdas (Intelligence System) adalah sistem yang dibangun dengan menggunakan teknik- teknik Artificial Intelligence"(Septiani \& Kuryanti, 2019).Ada tiga tujuan kecerdasan buatan yaitu "membuat komputer lebih cerdas, mengerti tentang kecerdasan, dan membuat mesin lebih berguna". Kecerdasan disini dimaksudkan dengan kemampuan untuk belajar atau mengerti dari pengalaman, mampu memahami pesan yang kontradiktif ataupun ambigu, mampu menanggapi dengan cepat dan baik atas situasi baru, dan menggunakan penalaran yang baik dalam 
memecahkan masalah serta menyelesaikannya dengan efektif(Septiani \& Kuryanti, 2019).

\subsection{Sistem Pakar}

Sistem Pakar adalah salah satu cabang dari Artificial Intelligence (AI) yang membuat penggunaan secara luas pengetahuan atau knowledge yang khusus untuk penyelesaian masalah tingkat manusia yang pakar. Sistem Pakar terdiri dari dua bagian utama, yaitu lingkungan pengembangan (development environment) dan lingkungan konsultasi (consultation environment). Lingkungan pengembang pada sistem pakar digunakan sebagai pintu masuk pengetahuan pakar ke dalam lingkungan sistem pakar, sedangkan lingkungan konsultasi akan digunakan pengguna yang bukan pakar dalam memperoleh pengetahuan pakar(Handoko et al., 2019).

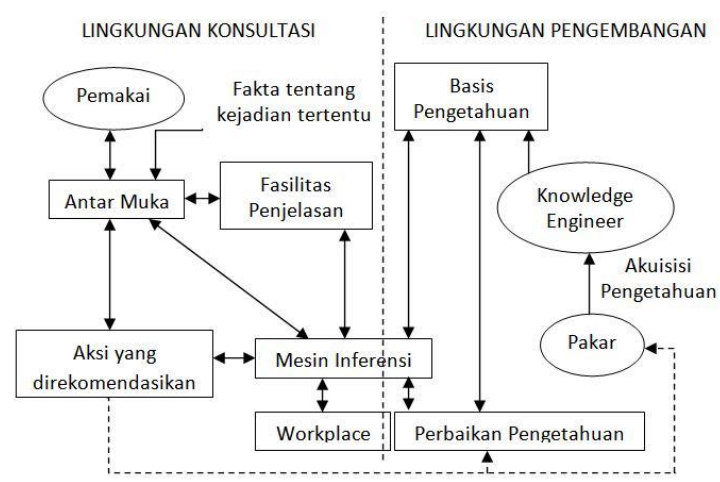

Gambar 1. Arsitektur Sistem

Pakar(Fairuzelsaid, 2017)

\subsection{Forward Chaining}

Suatu rantai yang dicari atau dilewati dari suatu permasalahan untuk memperoleh solusinya disebut forward chaining.Forward chaining adalah contoh dari konsep umum, dimana fokus perhatian dari penalaran dimulai dari data yang dikenal. Dari definisi tersebut dapat disimpulkan bahwa forward chaining adalah suatu metode pencarian fakta dimana fokus penalaran mulai dari data yang dikenal dan berakhir pada sebuah solusi(Handoko et al., 2019).

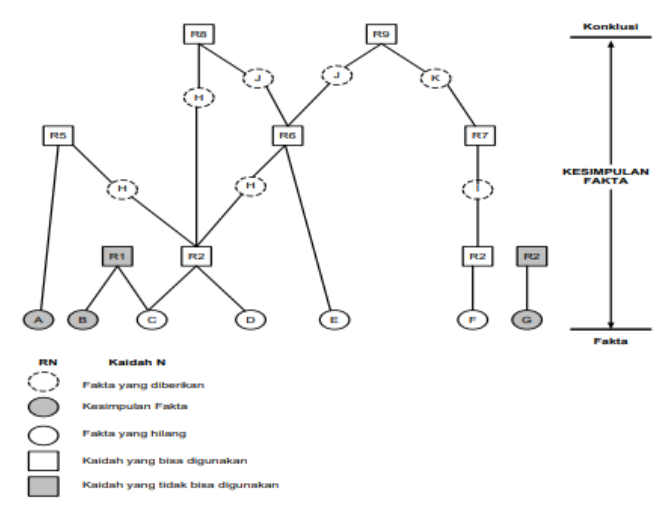

Gambar 2.Forward Chaining(Handoko et al., 2019)

Menurut Giarattano dan Riley (1994), metode inferensi forward chaining cocok digunakan untuk menangani masalah pengendalian (controlling) dan peramalan (prognosis)(Tanshidiq, Agtian Muhamad Ricky, Hartanto, Anggit Dwi, Prabowo, 2017). Pengetahuan dalam kaidah penulisan produksi direpresentasikan dalam bentuk:

\section{JIKA [antecedent] MAKA [konsekuen]}

$$
\text { JIKA [kondisi] MAKA [aksi] }
$$

JIKA [premis] MAKA [konklusi]

Aturan dalam kaidah produksi diklasifikasikan menjadi kaidah derajat pertama dan kaidah meta. Kaidah derajat pertama adalah aturan yang bagian konklusinya tidak menjadi premis bagi kaidah lain. Sebaliknya, kaidah meta merupakan kaidah yang konklusinya merupakan premis bagi kaidah yang lain(Tanshidiq, Agtian Muhamad Ricky, Hartanto, Anggit Dwi, Prabowo, 2017). 
Berikut ini menunjukan bagaimana cara kerja metode inferensi forward chaining : DATA ATURAN KESIMPULAN

$\mathrm{A}=1$

$\mathrm{B}=2$

JIKA A $=1$ DAN B $=2$

MAKA C $=3 \quad \mathrm{D}=4$

JIKA C $=3$ MAKA D $=4$

\subsection{Malnutrisi}

Malnutrisi adalah kondisi gizi yang tidak seimbang. Ini berarti, malnutrisi tidak hanya mengacu pada kondisi kekurangan asupan makan (undernutrition).Istilah malnutrisi juga bisa digunakan untuk menggambarkan orang yang makan dengan cukup, tapi nutrisinya tidak seimbang (unbalanced diet), serta individu dengan kelebihan berat badan (overweight)(Rafiqua, 2020).

Menurut badan kesehatan dunia World Health Organization (WHO), malnutrisi mencakup berbagai kondisi yang terkait dengan gizi. Beberapa di antaranya adalah:(Rafiqua, 2020).

a) Kekurangan gizi atau undernutrition, contohnya pada kondisi underweight (terlalu kurus untuk usianya), wasting (terlalu kurus untuk tinggi badannya), serta stunting (terlalu pendek untuk usianya)

b) Nutrisi yang tidak seimbang, contohnya kekurangan dan kelebihan mikronutrisi vitamin dan mineral

c) Kelebihan berat badan dan obesitas

d) Penyakit tak menular yang terkait pola makan, seperti penyakit jantung, stroke, diabetes, dan beberapa tipe kanker.

Secara global, WHO juga memperkirakan ada 1,9 juta orang dewasa yang terlalu gemuk dan 462 juta orang dewasa dengan kondisi kelewat kurus.
Malnutrisi sering terjadi pada negara berpenghasilan rendah hingga sedang(Rafiqua, 2020).

\section{METODE PENELITIAN}

Metode penelitian merupakan langkah yang dimiliki dan dilakukan oleh peneliti dalam rangka untuk mengumpulkan informasi atau data serta melakukan investigasi pada data yang telah didapatkan tersebut.Pada penelitian ini menggunakan metode deskriptif yaitu metode yang bertujuan untuk membuat deskripsi secara sistematis, faktual, serta akurat pada fakta.Pada metode ini juga membahas masalah dengan memaparkan suatu keadaan atau peristiwa kemudian dianalisis dan di ambil kesimpulan umum dari masalah yang di bahas(Hakim Rahman, 2018).Ada beberapa langkah kerja pada metode ini,langkah tersebut secara detail sebagai berikut:

\subsection{Deskripsi Masalah}

Deskripsi Masalah merupakan tehapan mendeskripsikan masalah dengan memutuskan dan menentukan batasan dari masalah,untuk mendapatkan solusi atas masalah tersebut.

\subsection{Analisa Masalah}

Pada tahap analisis ini,proses berlanjut memahami masalah yang telah di putuskan dan dibatasi.Dengan melakukan analisis masalah ini,diharapkan dapat membantu dalam memhami masalah dengan lebih baik.

\subsection{Pengumpulan Data}

Untuk pengumpulan data,penulis akan mengumpulakan data dan informasi penting dan akurat sesui fakta yang ada untuk membantu menunjang proses penelitian ini,pada pengumpulan data ada beberapa metode yang di gunakan antara 
lain: Studi Literatur, Wawancara, Pengamatan dan Studi Pustaka

\subsection{Analisis Sistem}

Analisis Sistem atau System Analysis adalah suatu teknik atau metode pemecahan masalah dengan cara menguraikan sistem ke dalam komponen-komponen pembentuknya untuk mengetahui bagaimana komponen-komponen tersebut bekerja dan saling berinteraksi satu sama lain untuk mencapai tujuan sistem.

Pada tahap ini data yang terkumpul dari lokasi penelitian selanjutnya di analisa dengan menggunakan metode forward chaining,kemudian diberikan perancangan layout program user interface untuk memudahkan pengguna dalam mengakses komponen-komponen dari sistem pakar tersebut.

\subsection{Perancangan Sistem}

Pada tahapan perancancangan sistem,penulis akan dimudahkan dalam penentuan bahasa program yang di gunakan dalam penelitian.Pada penelitian ini,penulis akan menggunakan bahasa php dan mysql.Sedangkan untuk pemodelannya penulis akan menggunakan Unified Modeling Language (UML)(Arifin et al., n.d.).

\subsection{Pengujian}

Pengujian merupakan tahapan untuk memeriksa apakah sistem yang di rancang sudah sesuai dengan yang di harapakan.

\section{HASIL DAN PEMBAHASAN}

\subsection{Analisis sistem}

Pada analisis sistem ini, tujuannya mengidentifikasi masalah yang terjadi pada sistem pakar mendeteksi malnutrisi pada remaja,untuk mengembangkan sistem berdasarkan data yang dikupulkan.Analisis ini dilakukan agar sistem pakar yang di kembangkan dapat menjadi lebih baik dan bisa membantu pengguna atau orang tua dalam mendeteksi gangguan gizi yang dialami oleh anak remajanya.Dalam menentukan penyakit malnutrisi yang di alami remaja,penulis menganalisis gejala malnutrisi yang dialami oleh remaja dari berbagai referensi untuk menarik kesimpulan dan memberikan saran terhadap gejala malnutrisi yang dialami oleh remaja.Saat ini banyak remaja yang terserang malnutrisi di sebabkan oleh beberapa factor dan kebiasaan remaja itu sendiri.

\subsection{Analisis data}

Analisis data merupakan tahapan untuk membatasi data agar menjadi lebih teratur ketika pengolahan data penelitian.Pada penelitian ini menggunakan tabel pakar yang di peroleh dari web pakar,ilmu pengetahuan,dan penelitian.

Adapun data-data yang telah di kumpulkan sebagai berikut:

Table 1. Tabel Penyakit

\begin{tabular}{|l|l|}
\hline Kode Penyakit & Nama Penyakit \\
\hline P001 & Kwashiorkor \\
\hline P002 & Marasmus \\
\hline P003 & Beri-Beri Basah \\
\hline P004 & Beri-Beri Kering \\
\hline P005 & Skorbut \\
\hline
\end{tabular}

Table 2. Tabel Gejala

\begin{tabular}{|l|l|}
\hline \multicolumn{1}{|c|}{ Kode Gejala } & \multicolumn{2}{|c|}{ Nama Gejala } \\
\hline G001 & Kelelahan \\
\hline G002 & $\begin{array}{l}\text { Warna kulit dan } \\
\text { Rambut berubah } \\
\text { oranye }\end{array}$ \\
\hline
\end{tabular}




\begin{tabular}{|c|c|}
\hline Kode Gejala & Nama Gejala \\
\hline & $\begin{array}{l}\text { kemerahan,kuning,atau } \\
\text { putih }\end{array}$ \\
\hline G003 & $\begin{array}{ll}\text { Sistem kekebalan } \\
\text { tubuh rusak }\end{array}$ \\
\hline G004 & Hilangnya massa otot \\
\hline G005 & $\begin{array}{l}\text { pembengkakan di } \\
\text { bawah kulit (edema) }\end{array}$ \\
\hline G006 & mudah marah \\
\hline G007 & $\begin{array}{l}\text { Susah menambah berat } \\
\text { badan dan tinggi badan }\end{array}$ \\
\hline G008 & perut buncit \\
\hline G009 & kulit mengalami ruam \\
\hline G010 & Mudah syok \\
\hline G011 & Tubuh Kurus Kering \\
\hline G012 & $\begin{array}{l}\text { wajah seperti orang } \\
\text { yang sudah tua }\end{array}$ \\
\hline G013 & $\begin{array}{ll}\text { denyut } & \text { jantung } \\
\text { meningkat } & \end{array}$ \\
\hline G014 & sesak napas \\
\hline G015 & $\begin{array}{l}\text { kaki bagian bawah } \\
\text { bengkak }\end{array}$ \\
\hline G016 & susah berjalan \\
\hline G017 & $\begin{array}{l}\text { kaki dan tangan mati } \\
\text { rasa atau kesemutan }\end{array}$ \\
\hline G018 & nyeri \\
\hline G019 & kesulitan bicara \\
\hline G020 & muntah \\
\hline G021 & nistagmus \\
\hline G022 & $\begin{array}{lr}\text { perdarahan } & \text { dan } \\
\text { pembengkakan } & \text { pada } \\
\text { gusi } & \end{array}$ \\
\hline G023 & berat badan turun \\
\hline G024 & diare \\
\hline G025 & mual \\
\hline G026 & demam \\
\hline G027 & tubuh lemah dan lesu \\
\hline G028 & kesemutan di kaki \\
\hline
\end{tabular}

\begin{tabular}{|l|l|}
\hline \multicolumn{1}{|c|}{ Kode Gejala } & \multicolumn{1}{|c|}{ Nama Gejala } \\
\hline G029 & $\begin{array}{l}\text { kurangnya nafsu } \\
\text { makan }\end{array}$ \\
\hline G030 & detak jantung cepat \\
\hline G031 & kuku rapuh \\
\hline G032 & radang lidah (glositis) \\
\hline G033 & $\begin{array}{l}\text { tangan dan kaki dingin } \\
\text { kepala atau sakit }\end{array}$ \\
\hline G034 & infeksi \\
\hline G035 & sakit dada \\
\hline G036 & insomnia \\
\hline G037 & kulit pucat \\
\hline G038 & \\
\hline
\end{tabular}

Table 3. Tabel Pertanyaan

\begin{tabular}{|c|c|c|c|}
\hline No & Pertanyaan & Iya & tidak \\
\hline 1. & $\begin{array}{l}\text { Apakah anak anda } \\
\text { terlihat } \\
\text { kelelahan? }\end{array}$ & & \\
\hline 2. & $\begin{array}{l}\text { Apakah warna kulit dan } \\
\text { rambut anak anda } \\
\text { berubah menjadi oranye } \\
\text { kemerahan, kuning, atau } \\
\text { bahkan putih? }\end{array}$ & & \\
\hline 3. & $\begin{array}{l}\text { Apakah Pada sistem } \\
\text { kekebalan tubuh anak } \\
\text { anda ada masalah? }\end{array}$ & & \\
\hline 4. & $\begin{array}{l}\text { Apakah otot anak anda } \\
\text { cenderung lebih kecil? }\end{array}$ & & \\
\hline 5. & $\begin{array}{l}\text { Apakah anak anda ada } \\
\text { mengalami } \\
\text { pembengkakan di bawah } \\
\text { kulit (edema)? }\end{array}$ & & \\
\hline 6. & $\begin{array}{l}\text { Apakah anak anda } \\
\text { mudah marah? }\end{array}$ & & \\
\hline 7. & $\begin{array}{l}\text { Apakah anak anda susah } \\
\text { menambah berat badan } \\
\text { dan menambah tinggi } \\
\text { badan? }\end{array}$ & & \\
\hline
\end{tabular}




\begin{tabular}{|c|c|c|c|}
\hline No & Pertanyaan & Iya & tidak \\
\hline 8. & $\begin{array}{l}\text { Apakah perut anak anda } \\
\text { buncit? }\end{array}$ & & \\
\hline 9. & $\begin{array}{l}\text { Apakah kulit anak anda } \\
\text { mengalami ruam? }\end{array}$ & & \\
\hline 10. & $\begin{array}{l}\text { Apakah anak anda } \\
\text { mudah syok? }\end{array}$ & & \\
\hline 11. & $\begin{array}{l}\text { Apakah tubuh anak anda } \\
\text { terlihat kurus kering? }\end{array}$ & & \\
\hline 12. & $\begin{array}{l}\text { Apakah wajah anak anda } \\
\text { seperti orang yang sudah } \\
\text { tua? }\end{array}$ & & \\
\hline 13. & $\begin{array}{l}\text { Apakah anak anda ada } \\
\text { merasa denyut } \\
\text { jantungnya meningkat? }\end{array}$ & & \\
\hline 14. & $\begin{array}{l}\text { Apakah anak anda ada } \\
\text { mengalami sesak napas? }\end{array}$ & & \\
\hline 15. & $\begin{array}{l}\text { Apakah kaki bagian } \\
\text { bawah anak anda terlihat } \\
\text { bengkak? }\end{array}$ & & \\
\hline 16. & $\begin{array}{l}\text { Apakah anak } \begin{array}{l}\text { anda } \\
\text { mengalami } \\
\text { berjalan? }\end{array} \\
\text { susah } \\
\end{array}$ & & \\
\hline 17. & $\begin{array}{l}\text { Apakah anak anda ada } \\
\text { merasakan kaki dan } \\
\text { tangannya mati rasa atau } \\
\text { kesemutan? }\end{array}$ & & \\
\hline 18. & $\begin{array}{l}\text { Apakah anak anda ada } \\
\text { merasakan nyeri? }\end{array}$ & & \\
\hline 19. & $\begin{array}{l}\text { Apakah anak anda } \\
\text { kesulitan bicara? }\end{array}$ & & \\
\hline 20. & $\begin{array}{l}\text { Apakah anak anda } \\
\text { memiliki gejala muntah? }\end{array}$ & & \\
\hline 21. & $\begin{array}{l}\text { Apakah gerakan pada } \\
\text { bola mata anak anda } \\
\text { terlihat tidak terkendali? }\end{array}$ & & \\
\hline 22 & $\begin{array}{l}\text { Apakah anak anda } \\
\text { mengalami } \\
\text { pembengkakan pada } \\
\text { gusi? }\end{array}$ & & \\
\hline 23. & $\begin{array}{l}\text { Apakah anak anda ada } \\
\text { mengalami berat } \\
\text { badannya turun? }\end{array}$ & & \\
\hline
\end{tabular}

\begin{tabular}{|c|c|c|c|}
\hline No & Pertanyaan & Iya & tidak \\
\hline 24. & $\begin{array}{l}\text { Apakah anak anda ada } \\
\text { mengalami sakit diare? }\end{array}$ & & \\
\hline 25. & $\begin{array}{l}\text { Apakah anak anda } \\
\text { mengalami mual? }\end{array}$ & & \\
\hline 26. & $\begin{array}{l}\text { Apakah anak anda } \\
\text { mengalami demam? }\end{array}$ & & \\
\hline 27. & $\begin{array}{l}\text { Apakah anak anda } \\
\text { terlihat lemah dan lesu? }\end{array}$ & & \\
\hline 28. & $\begin{array}{l}\text { Apakah anak anda ada } \\
\text { merasa kesemutan di } \\
\text { kaki? }\end{array}$ & & \\
\hline 29. & $\begin{array}{l}\text { Apakah anak anda } \\
\text { mengalami kurangnya } \\
\text { nafsu makan? }\end{array}$ & & \\
\hline 30. & $\begin{array}{l}\text { Apakah anak anda ada } \\
\text { merasa detak jantungnya } \\
\text { meningkat? }\end{array}$ & & \\
\hline 31. & $\begin{array}{l}\text { Apakah anak anda } \\
\text { mengalami kerapuhan } \\
\text { pada kukunya? }\end{array}$ & & \\
\hline 32. & $\begin{array}{l}\text { Apakah anak anda } \\
\text { mengalami radang lidah } \\
\text { (glositis)? }\end{array}$ & & \\
\hline 33. & $\begin{array}{l}\text { Apakah tangan dan kaki } \\
\text { anak anda dingin? }\end{array}$ & & \\
\hline 34. & $\begin{array}{l}\text { Apakah anak anda } \\
\text { mengalami pusing atau } \\
\text { sakit kepala? }\end{array}$ & & \\
\hline 35. & $\begin{array}{l}\text { Apakah anak ada ada } \\
\text { mengalami infeksi? }\end{array}$ & & \\
\hline 36. & $\begin{array}{l}\text { Apakah anak anda ada } \\
\text { mengalami sakit pada } \\
\text { dada? }\end{array}$ & & \\
\hline 37. & $\begin{array}{l}\text { Apakah anak anda ada } \\
\text { mengalami insomnia? }\end{array}$ & & \\
\hline 38. & $\begin{array}{l}\text { Apakah kulit anak anda } \\
\text { terlihat pucat? }\end{array}$ & & \\
\hline
\end{tabular}

\subsection{Analisis Proses}

Pada sistem pakar ini,untuk pemgetahuan dan informasi diambil dari beberapa sumber seperti website bidang kesehatan,jurnal dan lain-lain.Untuk 
aturan-aturan yang di gunakan berdasarkan pada pengetahuan dari referensi yang telah didapatkan.Pengetahuan tersebut akan di terapkan dalam bentuk aturan yang akan di gunakan untuk menarik kesimpulan dan memberikan seolusi terhadap masalah.Rule-rule yang akan di gunakan untuk mendeteksi malnutrisi pada remaja adalah sebagai berikut:

Table 4. Tabel Rule Pakar

\begin{tabular}{|c|c|}
\hline G001 & If Mudah kelelahan and \\
\hline G002 & 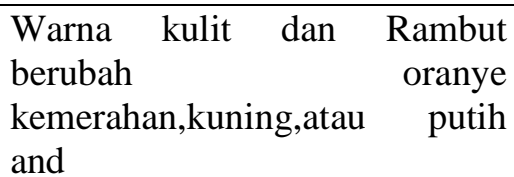 \\
\hline G003 & $\begin{array}{l}\text { Sistem kekebalan tubuh rusak } \\
\text { and }\end{array}$ \\
\hline G004 & Hilangnya massa otot and \\
\hline G005 & $\begin{array}{l}\text { pembengkakan di bawah kulit } \\
\text { (edema) and }\end{array}$ \\
\hline G006 & mudah marah and \\
\hline G007 & $\begin{array}{l}\text { Susah menambah berat badan } \\
\text { dan tinggi badan and }\end{array}$ \\
\hline G008 & perut buncit and \\
\hline G009 & kulit mengalami ruam and \\
\hline G010 & Mudah syok then \\
\hline P001 & Kwashiorkor \\
\hline G011 & Tubuh Kurus Kering and \\
\hline G012 & $\begin{array}{l}\text { wajah seperti orang yang sudah } \\
\text { tua then }\end{array}$ \\
\hline P002 & Marasmus \\
\hline G014 & sesak napas and \\
\hline G013 & denyut jantung meningkat and \\
\hline G015 & kaki bagian bawah bengkak then \\
\hline P003 & Beri-Beri Basah \\
\hline
\end{tabular}

\begin{tabular}{|c|c|}
\hline G016 & susah berjalan and \\
\hline G017 & $\begin{array}{l}\text { kaki dan tangan mati rasa atau } \\
\text { kesemutan and }\end{array}$ \\
\hline G018 & Nyeri and \\
\hline G019 & kesulitan bicara and \\
\hline G020 & Muntah and \\
\hline G021 & Nistagmus then \\
\hline P004 & Beri-Beri Kering \\
\hline G018 & Nyeri and \\
\hline G009 & kulit mengalami ruam and \\
\hline G022 & $\begin{array}{l}\text { perdarahan dan pembengkakan } \\
\text { pada gusi and }\end{array}$ \\
\hline G029 & kurangnya nafsu makan and \\
\hline G023 & berat badan turun and \\
\hline G024 & Diare and \\
\hline G025 & Mual and \\
\hline G026 & Demam then \\
\hline P005 & Skorbut \\
\hline G027 & tubuh lemah dan lesu and \\
\hline G001 & Mudah Kelelahan and \\
\hline G028 & kesemutan di kaki and \\
\hline G029 & kurangnya nafsu makan and \\
\hline G030 & detak jantung cepat and \\
\hline G031 & kuku rapuh and \\
\hline G018 & Nyeri and \\
\hline G032 & radang lidah (glositis) and \\
\hline G033 & tangan dan kaki dingin and \\
\hline G034 & pusing atau sakit kepala and \\
\hline G035 & Infeksi and \\
\hline G036 & sakit dada and \\
\hline G014 & sesak napas and \\
\hline G038 & Insomnia and \\
\hline G039 & Kulit Pucat then \\
\hline P006 & Anemia \\
\hline
\end{tabular}


Table 5. Tabel Relasi Pakar

\begin{tabular}{|c|c|c|c|c|c|c|c|}
\hline Kode & Nama & P0 & P0 & P0 & P0 & P0 & P0 \\
\hline & Gejala & 01 & 02 & 03 & 04 & 05 & \\
\hline G001 & $\begin{array}{l}\text { Mudah } \\
\text { kelelah } \\
\text { an }\end{array}$ & $\mathrm{v}$ & & & & & $\mathrm{V}$ \\
\hline G002 & $\begin{array}{l}\text { Warna } \\
\text { kulit } \\
\text { dan } \\
\text { Rambu } \\
\text { t } \\
\text { beruba } \\
\text { h } \\
\text { oranye } \\
\text { kemera } \\
\text { han,ku } \\
\text { ning,at } \\
\text { au } \\
\text { putih }\end{array}$ & $\mathrm{v}$ & & & & & \\
\hline G003 & $\begin{array}{l}\text { Sistem } \\
\text { kekeba } \\
\text { lan } \\
\text { tubuh } \\
\text { rusak }\end{array}$ & $\mathrm{v}$ & & & & & \\
\hline G004 & $\begin{array}{l}\text { Hilang } \\
\text { nya } \\
\text { massa } \\
\text { otot }\end{array}$ & $\mathrm{v}$ & & & & & \\
\hline G005 & $\begin{array}{l}\text { pembe } \\
\text { ngkaka } \\
\text { n di } \\
\text { bawah } \\
\text { kulit } \\
\text { (edema } \\
\text { ) }\end{array}$ & $\mathrm{V}$ & & & & & \\
\hline G006 & $\begin{array}{l}\text { mudah } \\
\text { marah }\end{array}$ & $\mathrm{v}$ & & & & & \\
\hline G007 & $\begin{array}{l}\text { Susah } \\
\text { menam } \\
\text { bah } \\
\text { berat } \\
\text { badan } \\
\text { dan } \\
\text { tinggi } \\
\text { badan }\end{array}$ & $\mathrm{V}$ & & & & & \\
\hline G008 & $\begin{array}{l}\text { perut } \\
\text { buncit }\end{array}$ & $\mathrm{v}$ & & & & & \\
\hline
\end{tabular}

\begin{tabular}{|c|c|c|c|c|c|c|c|}
\hline G009 & $\begin{array}{l}\text { kulit } \\
\text { mengal } \\
\text { ami } \\
\text { ruam }\end{array}$ & $\mathrm{v}$ & & & & $\mathrm{v}$ & \\
\hline G010 & $\begin{array}{l}\text { Mudah } \\
\text { syok }\end{array}$ & $\mathrm{v}$ & & & & & \\
\hline G011 & $\begin{array}{l}\text { Tubuh } \\
\text { Kurus } \\
\text { Kering }\end{array}$ & & $\mathrm{v}$ & & & & \\
\hline G012 & $\begin{array}{l}\text { wajah } \\
\text { seperti } \\
\text { orang } \\
\text { yang } \\
\text { sudah } \\
\text { tua }\end{array}$ & & $\mathrm{V}$ & & & & \\
\hline G013 & $\begin{array}{l}\text { denyut } \\
\text { jantung } \\
\text { mening } \\
\text { kat }\end{array}$ & & & $\mathrm{v}$ & & & \\
\hline G014 & $\begin{array}{l}\text { sesak } \\
\text { napas }\end{array}$ & & & $\mathrm{v}$ & & & $\mathrm{v}$ \\
\hline G015 & $\begin{array}{l}\text { kaki } \\
\text { bagian } \\
\text { bawah } \\
\text { bengka } \\
\text { k }\end{array}$ & & & $\mathrm{V}$ & & & \\
\hline G016 & $\begin{array}{l}\text { susah } \\
\text { berjala } \\
\mathrm{n}\end{array}$ & & & & $\mathrm{V}$ & & \\
\hline G017 & $\begin{array}{l}\text { kaki } \\
\text { dan } \\
\text { tangan } \\
\text { mati } \\
\text { rasa } \\
\text { atau } \\
\text { kesem } \\
\text { utan }\end{array}$ & & & & $\mathrm{V}$ & & \\
\hline G018 & Nyeri & & & & $\mathrm{v}$ & $\mathrm{v}$ & $\mathrm{v}$ \\
\hline G019 & $\begin{array}{l}\text { kesulit } \\
\text { an } \\
\text { bicara }\end{array}$ & & & & $\mathrm{V}$ & & \\
\hline G020 & $\begin{array}{l}\text { Munta } \\
\text { h }\end{array}$ & & & & $\mathrm{V}$ & & \\
\hline G021 & $\begin{array}{l}\text { Nistag } \\
\text { mus }\end{array}$ & & & & $\mathrm{V}$ & & \\
\hline G022 & $\begin{array}{l}\text { perdara } \\
\text { han }\end{array}$ & & & & & $\mathrm{v}$ & \\
\hline
\end{tabular}




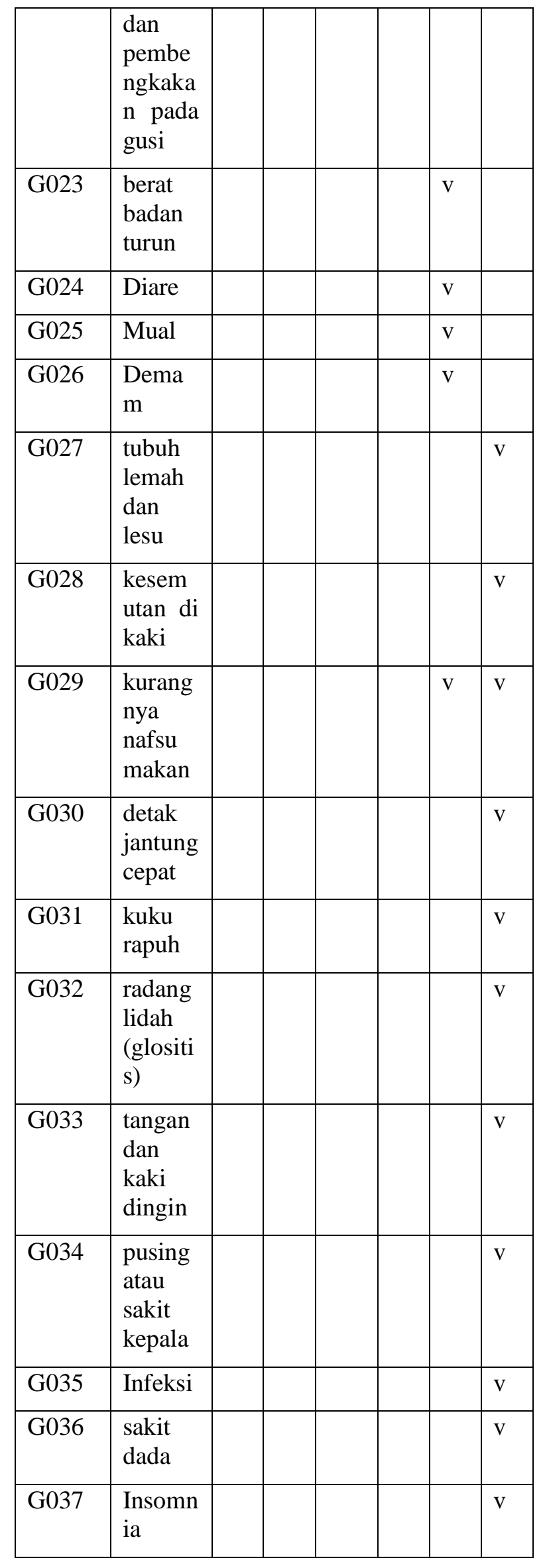

\begin{tabular}{|l|l|l|l|l|l|l|l|}
\hline G038 & $\begin{array}{l}\text { Kulit } \\
\text { Pucat }\end{array}$ & & & & & & v \\
\hline
\end{tabular}

\subsection{Desain UML}

Sebagai alat bantu dalam perancangan sistem pakar ini, menggunakan Unified Modeling Language (UML) sebagai bahasa permodelan.Disini menggunakan use case diagram dimana use case ini di gunakan untuk mendapatkan kebutuhan fungsional dari suatu sistem.Pada use case ini menggambarkan bagaimana interaksi antara pengguna dengan sistem.

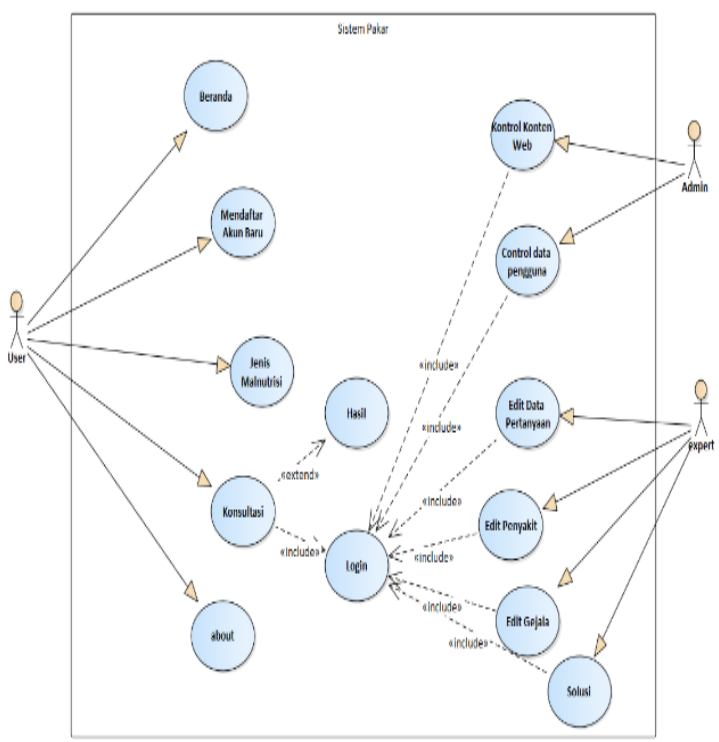

Gambar 3. use case diagram

Kemajuan teknologi yang pesat, hasil dari pemikiran dan pelatihan manusia yang cerdas, telah berkembang suatu teknologi yang mampu mengadopsi proses berpikir dan cara kerja manusia yaitu kecerdasan buatan atau Artificial Intelligence (AI).Artificial Intelligence (AI) memiliki berbagai macam aplikasi yang salah satunya adalah sistem pakar. Sistem pakar dengan metode fordward chaining disini diterapkan untuk mengidentifikasi malnutrisi pada remaja.Pengetahuan diperoleh dari website kementrian kesehatan republic Indonesia yang di tinjau langsung oleh pakar dari bidang kesehatan. 
Data diambil berdasarkan pertanyaan yang diajukan kepada pengguna dan apabila semua pertanyaan yang bersangkutan telah dilengkapi maka akan muncul hasil berupa jenis malnutrisi yang dialami dan saran terhadap jenis malnutrisi tersebut.Dengan penerapan sistem ini pengguna dapat mengetahui jenis penyakit yang menyerang anak remajanya dan mendapatkan solusi untuk penyakit tersebut.Dalam sistem ini juga disertakan informasi tentang jenis penyakit malnutrisi dan solusi dari penyakit tersebut sehingga dapat menambah pengetahuan orang tua tentang kesehatan anak remajanya khususnya pencegahan gizi buruk.

4.5.Implementasi dan pengujian

a) Halaman utama website

Halaman utama website sistem pakar mendeteksi malnutrisi pada remaja,berisi menu-menu dari website dan penjelasan tentang malnutrisi serta bahaya dari malnutrisi.

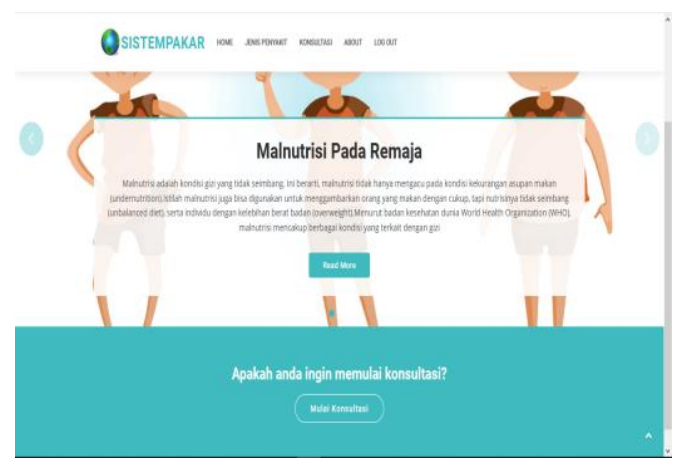

Gambar 4. Tampilan Halaman Utama

b) Halaman Login

Halaman login digunakan agar pengguna yang ingin berkonsultasi tentang kondisi anak remajanya dapat melakukan konsultasi.

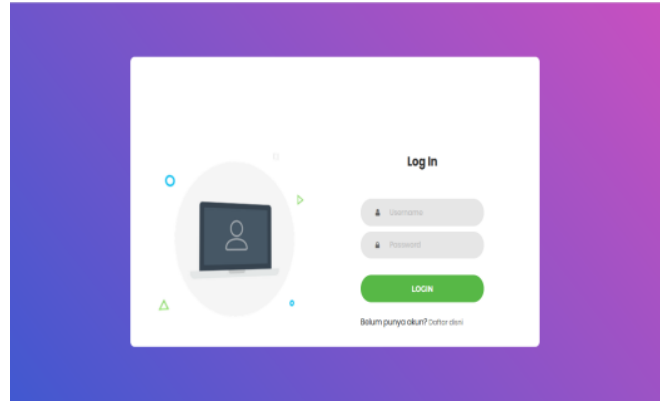

Gambar 5. Tampilan Halaman Login

c) Halaman Jenis penyakit

Merupakan halaman yang menginformasikan jenis-jenis penyakit yang diakibakan dari malnutrisi itu sendiri beserta gejala dan solusi untuk mengatasi penyakit tersebut.

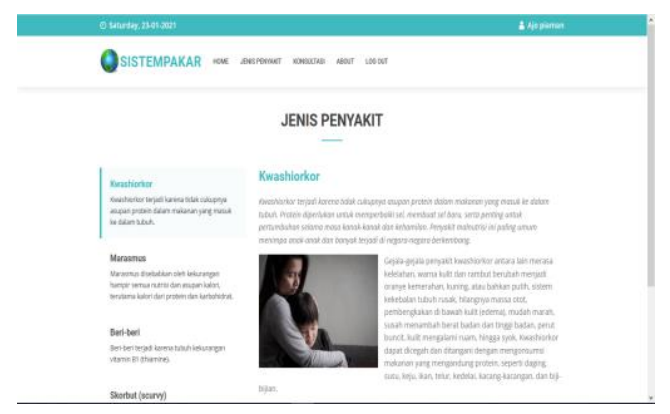

Gambar 6. Tampilan Halaman Jenis Penyakit

d) Halaman Konsultasi

Pengguna yang telah login dapat mengakses halaman konsultasi,untuk melakukan konsultasi seputar keadaan anak remajanya,dengan menjawab pertanyaan-pertanyaan yang di ajukan oleh sistem.

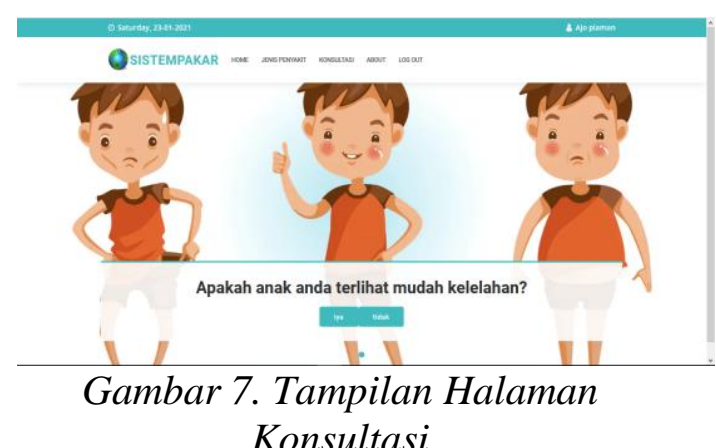


e) Halaman Hasil Konsultasi

Setelah menjawab semua pertanyaan yang di ajukan oleh sistem,selanjutkan akan tampil hasil diagnosis penyakit yang diderita oleh anak remaja anda.lalu pada website akan menampilkan gejala yang dialami oleh anak sesuai jawaban atas pertanyaannya dan solusi dari penyakit tersebut.

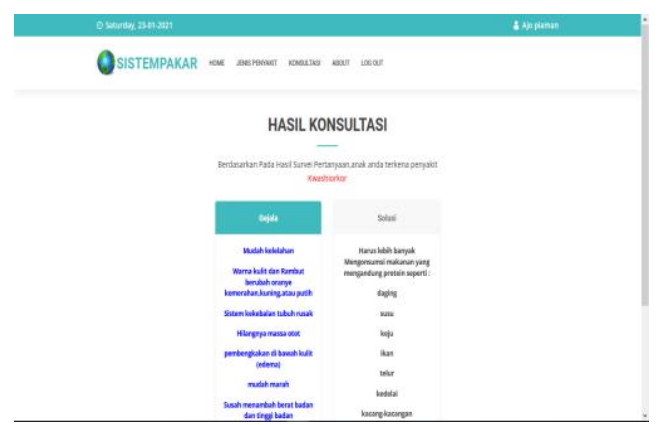

Gambar 8. Tampilan Hasil dari konsultasi

\section{SIMPULAN DAN SARAN}

Penyakit malnutrisi termasuk penyakit berbahaya,selain dapat menyebabkan gangguan pertumbuhan fisik dari anak juga mempengaruhi kecerdasan dari anak tersebut.Malnutrisi tidak hanya menyerang balita tetapi anak remaja,juga sering tekena penyakit malnutrisi ini.Oleh karena itu pemahaman dan pengetahuan tentang gizi ,serta upaya perbaikan gizi itu sangat penting,untuk melakukan pencegahan dari kemungkinan terburuk yang akan terjadi.Aplikasi sistem pakar mendeteksi malnutrisi pada remaja adalah suatu aplikasi yang digunakan untuk mendeteksi jenis penyakit serta solusi dari penyakit yang dilami remaja akibat gizi buruk, berdasarkan pengetahuan dari pakar dan studi pustaka.Dengan adanya akses online berbasis web diharapkan bagi orang tua dapat dengan mudah mendeteksi bahwa anak remajanya mengalami malnutrisi,sehingga orang tua dapat dengan cepat menangani masalah malnutrisi pada anak remajanya sebelum terjadi kemungkinan terburuknya.Aplikasi sistem pakar mendeteksi malnutrisi pada remaja ini dibuat berbasis web,sehingga dapat memudahkan pengguna untuk berkonsultasi dimana saja dan kapan saja pengguna inginkan.

Sistem pakar ini masih dapat di kembangkan dengan menggunakan metode lain,agar memperoleh hasil penilaian yang lebih optimal.Untuk data gejala-gejala gizi buruk diharapkan dapat di tambah lebih banyak agar pengguna lebih tahu secara detail ciri-ciri gejala dari gizi buruk tersebut.Untuk materi jenis penyakitnya, diharapkan dapat diperbanyak untuk menambah wawasan orang tua tentang penyakit apa saja yang dapat terjadi akibat gizi buruk.

\section{DAFTAR PUSTAKA}

Arifin, M., Slamin, S. \& Retnani, W. E. Y. (2017). Penerapan Metode Certainty Factor Untuk Sistem Pakar Diagnosis Hama Dan Penyakit Pada Tanaman Tembakau. Jurnal Elektronik Berkala Sainstek (BST), 5(1), 21-28

Batam, D. I. K. (2017). Sistem Pakar Mendeteksi Tindak Pidana Cybercrime Menggunakan Metode Forward Chaining Berbasis Web Jurnal Edik Informatika. 2.

Danty, F. R., Syah, M. N. H., \& Sari, A. E. (2019). Hubungan Indeks Gizi Seimbang Dengan Status Gizi Pada Remaja Putri Di SMK Kota Bekasi. Jurnal Kesehatan Indonesia, 10(1), 43-54.

Fairuzelsaid. (2017). Sistem Pakar: Konsep Dasar. 
Www.Http://Fairuzelsaid.Upy.Ac.Id. http://fairuzelsaid.upy.ac.id/sisteminformasi/konsep-dasar-sistem-pakar/ Hakim Rahman, A. (2018). Membangun Sistem Penjualan Ikan Laut Berbasis Web Pada Cv.Famashena. Jurnal Rekayasa Informasi, 7(1), 59-67.

Handoko, A. R., Informasi, F. T., Studi, P., Informatika, T., \& Luhur, U. B. (2019). Perancangan sistem pakar analisa transaksi keuangan mencurigakan menggunakan metode forward chaining. 10(2), 701-712.

Kartika, D., Gema, R. L., \& Pratiwi, M. (2016). Expert Systems for Identifying Children ' s Severe Malnutrition. Journal of Computer Science and Information Technology, 2(October), 20-29.

Kementrian Kesehatan RI. (2020). Gizi saat Remaja Tentukan Kualitas Keturunan. 24 Januari 2020. https://www.kemkes.go.id/article/vie w/20012600004/gizi-saat-remajatentukan-kualitas-keturunan.html
Rafiqua, N. (2020). Malnutrisi. Www.Sehatq.Com. https://www.sehatq.com/penyakit/mal nutrisi

Septiani, M., \& Kuryanti, S. J. (2019). Sistem Pakar untuk Mendiagnosa Penyakit Saluran Pernapasan pada Anak. 2(April 2018), 23-27.

Tanshidiq, Agtian Muhamad Ricky, Hartanto, Anggit Dwi, Prabowo, D. (2017). Penerapan Metode Forward Chaining Pada Aplikasi Sistem Pakar Diagnosa Penyakit Pada Tanaman Bunga Kamboja (Adenium). Jurnal Ilmiah DASI, 18(2), 60.

Valentina, A. A. I. M. P., \& Debora, T. (2013). Hubungan Regulasi Diri Dengan Status Gizi pada Remaja Akhir di Kota Denpasar. Jurnal Psikologi Udayana, 1(1), 43-53. 